\title{
Lei ordinária em matéria penal: incongruência latente
}

\author{
Renata Okano Gimenes ${ }^{1}$
}

\section{Resumo}

\begin{abstract}
A atividade legislativa do Estado, na edição de leis em matéria penal, deve atentar aos bens jurídico-penais vazados na Constituição Federal. Ao resguardar referidos valores constitucionais, o legislador constitucional reservou algumas matérias a serem tratadas mediante lei complementar. Essas matérias, consideradas essencialmente relevantes para a condução da Federação, somente podem ser regulamentadas mediante quorum privilegiado e maioria absoluta, os quais não são exigidos no processo legislativo ordinário. Essa exigência mais rígida no rito de criação da lei complementar propicia um elastecimento da fase de discussão legislativa, que acarreta no cumprimento mais efetivo do princípio da ultima ratio do Direito Penal, de forma a utilizar o sistema penalístico somente nas situações realmente necessárias. Mostra-se, portanto, a lei complementar como o meio legal mais adequado à introdução de normais penais no ordenamento jurídico, no intuito potencializar a operabilidade do sistema penalístico, aproximando-se o dever-ser legislativo à realidade social e contribuindo para a estabilização da segurança jurídica.
\end{abstract}

Palavras-Chave: Direito Penal; Bem jurídico-penal; Lei Complementar.

\section{Introdução - Bem jurídico-penal e constituição}

A Constituição Federal, como fundamento de existência do ordenamento jurídico brasileiro, expande seus efeitos normativos a todos os setores do Direito, estreitando ligações especialmente na seara penal. As raízes materiais do Direito Penal - ao qual incumbe tutelar os bens e valores essenciais ao desenvolvimento do indivíduo e do bemestar social - encontram abrigo de validade na norma constitucional.

Fonte primeira da lei penal, a Carta Magna abrange normas de Direito Público, dentre as quais se destacam as garantias e direitos fundamentais, que constituem explícita ou implicitamente princípios basilares do Direito Penal. São princípios constitucionais penais atinentes ao Estado Democrático de Direito, impondo limitação instransponível ao jus puniendi estatal, que fornecem parâmetros à delimitação dos bens jurídico-penais.

1 Advogada, Juíza-Conciliadora dos Juizados Especiais Criminais de Londrina e Discente da Especialização em Direito Penal e Processo Penal da Universidade Estadual de Londrina. 
Para uma melhor avaliação da influência dos valores constitucionais no Direito Penal, deve-se levar em conta uma primeira distinção entre princípios (ou valores) constitucionais pertencentes à matéria penal e princípios de direito penal constitucional (PALAZZO, 1989, p. 22-23). Os primeiros possuem conteúdo heterogêneo, permeando diversos ramos do direito. Traçam o rumo disciplinador das matérias constitucionalmente relevantes, condicionando o conteúdo - e não a forma, como ocorre no princípio constitucional penal - da matéria a ser disciplinada. Isto é, determinam quais são os bens jurídicos resguardados pela Constituição que irão influenciar na formação do aspecto material das normas de Direito Penal.

Já os princípios de direito penal constitucional apresentam um conteúdo penalístico típico, delineando a feição constitucional do sistema penal. Possuem características substancialmente constitucionais dentro do poder punitivo do Estado, ressaltando a posição da pessoa humana no âmago do organograma penal, e fincam os termos essenciais da relação entre o indivíduo e o Estado na esfera do Direito Penal. Disciplinam a forma penal da tutela, o modo da disciplina penalística.

A idéia de bem jurídico - trazida tanto pelos princípios constitucionais pertencentes à matéria penal como pelos princípios de Direito Penal constitucional - é de extrema relevância, eis que a moderna ciência penal imprescinde de uma base empírica, de um vínculo com a realidade que lhe propicie uma razão de existência. De acordo com o princípio da exclusiva proteção do bem jurídico, todo delito deve lesar ou pôr em perigo de lesão determinado bem jurídico (PRADO, 2003).

O bem jurídico-penal deve estar sempre em consonância com o quadro axiológico vazado na Constituição. A ordem de valores jurídico-constitucionais constitui o quadro de referência e, simultaneamente, o critério regulador no âmbito de uma aceitável e necessária atividade punitiva do Estado, em forma de analogia substancial. Assim, a ordem de valores constitucionalmente relevantes constitui os liames do legislador penal infraconstitucional (PRADO, 2003).

Os valores penais mais importantes estão implícita ou expressamente inseridos na Constituição Federal. É ela o fundamento primeiro para a proteção dos bens socialmente relevantes resguardados pela seara penal. A construção dos tipos penais deve ser restrita, 
observando-se a gravidade dos danos sociais, o caráter subsidiário do direito penal ${ }^{2}$, o princípio da intervenção mínima ${ }^{3}$ e o princípio da fragmentariedade ${ }^{4}$. Mediante análise dos valores constitucionais sob essa luz principiológica, cabe ao jurista garimpar entre os bem jurídicos aqueles que merecem obter a dignidade penal, além de carecerem de sanção.

Nestes termos, foi elaborado pela Constituição um catálogo de condutas socialmente importantes, dignas de receberem a tutela penal. Tal listagem tem espeque nos valores constitucionais positivados e leva em conta os critérios da a) danosidade social, relacionada com o ataque ao bem jurídico; b) subsidiariedade, pertinente à intervenção penal na tutela de determinado bem jurídico; e c) tolerância, conceituada como a ponderação da média de sacrifício do bem jurídico que a sociedade deve suportar (SIRVINSKAS, 2003, p. 68).

Dignidade penal é a relevância dada ao bem que se quer proteger. O Direito Penal, como interventor subsidiário, somente está legitimado a atuar diante da insuficiência da tutela prévia, de caráter extrapenal, incidente sobre o fato, quando indispensável à manutenção da ordem jurídica ${ }^{5}$. Vencida a satisfatoriedade de outras medidas compositivas do litígio e recaindo o efeito da conduta na esfera de significado social relevante, o Direito Penal resta apto a intervir.

A substancialidade do bem jurídico põe em destaque a necessidade de uma valoração ética. Apenas as ações mais graves dirigidas contra bens fundamentais - que lesionem ou coloquem em perigo de lesão autênticos bens jurídicos - podem ser criminalizadas, de acordo com o adágio nullum criminem (nulla lex) sine injuria.

Neste sentido, preconizou o jurista espanhol Polaino Navarrete (apud PRADO, 2003, pp. 21-22)“sem a presença de um bem jurídico prevista no preceito punitivo, o próprio

2 Também chamado de ultima ratio, o princípio da subsidiariedade estabelece que o Direito Penal só deve atuar na defesa dos bens jurídicos imprescindíveis à coexistência pacífica dos homens (dignidade penal) e que não podem ser eficazmente protegidos de outra forma (carência de sanção).

3 A criação de tipos delituosos só deve ocorrer em casos imprescindíveis, devendo intervir o Direito Penal tão somente nos casos em que os demais ramos do direito restarem inaptos à prevenção da conduta ilícita. 0 princípio da intervenção mínima é uma orientação político-criminal limitativa do jus puniendi do Estado, referindo-se à intervenção estatal na vida do cidadão.

4 O Direito Penal é fragmentário eis que não tutela todas as lesões, mas só aquelas de maior gravidade, dirigidas contra bens valiosos, protegendo um fragmento dos interesses jurídicos, por meio de uma tutela seletiva. Nas palavras de Luiz Regis Prado (2002, p. 120): "Esse princípio impõe que o Direito Penal continue a ser um arquipélago de pequenas ilhas no grande mar do penalmente indiferente".

5 O uso excessivo da sanção criminal (inflação penal) não garante uma proteção maior dos bens; ao contrário, condena o sistema penal à inanidade (MAURACH apud PRADO, 2003, p. 68). 
Direito Penal, além de resultar materialmente injusto e ético-socialmente intolerável, careceria de sentido como tal ordem de direito".

O legislador deve se preocupar em considerar os valores fundamentais, sem desfigurar, através da tipicidade penal, o sentido que Ihes foi atribuído pela Carta Magna. Trata-se de uma denominação daquilo que é lícito considerar digno de proteção na perspectiva dos fins do Direito Penal.

Destarte, resta necessária a elaboração de um conceito material de delito a partir dos ditames jurídico-constitucionais, lastreado pela atividade legislativa penal de individualização dos valores que devem ser protegidos.

O delito corresponde a uma magnitude de valoração. Ao definir o injusto penal, assim apregoa Luiz Regis Prado (2003, p.36):

O injusto penal compreende a conduta culpável e ilícita. Do ponto de vista formal, é ilícita quando significa transgressão da norma estatal (mandato ou dever) e, em sentido material, quando opera uma lesão ou perigo de lesão a um interesse vital garantido pela norma (bem jurídico).

Logo, somente haverá delito quando ocorrer uma intolerável lesão, ou perigo de lesão, a um bem jurídico constitucionalmente relevante, digno de ser abraçado pela tutela penal.

Por outro lado, carência de sanção penal constitui-se na necessidade da utilização do instrumento sancionatório criminal atuante na proteção de determinado bem jurídico. Não é qualquer resultado antinormativo que justifica a intervenção penal. É preciso que haja afetação de bens jurídicos de terceiros (nunca o sacrifício de bens jurídicos próprios pode justificar a imposição de pena). Ademais, o resultado da transgressão da norma, além de transcendental, tem de ser significativo, intolerável, desvalioso, não amparado por outra norma jurídica e objetivamente imputável ao risco criado pela conduta do agente.

Neste sentido é o entendimento de Luiz Regis Prado (2003, p. 23):

A relação entre bem jurídico e pena opera uma simbiose entre o valor do bem jurídico e a função da pena: de um lado, tendo-se presente que se deve tutelar o que em si mesmo possui um valor, o marco da pena não é senão uma conseqüência imposta pela condição valiosa do bem; de outro lado, e ao mesmo tempo, a significação social do bem se vê confirmada precisamente porque para a sua proteção vem estabelecida a pena. Tudo isso contribui para concretizar os 
requisitos de capacidade e necessidade de proteção, que é comum se exigir dos bens jurídicos por ocasião de prever sua tutela.

Insuficiente que o bem jurídico seja valorado como essencialmente relevante. Impõe-se, ainda, que careça de uma sanção penal para o seu resguardo. Assim apregoa Octavio De Toledo Y Ubieto (apud GOMES, 2002, p. 59) :

\begin{abstract}
As leis penais não podem amparar com suas normas interesses incompatíveis com os acolhidos pela Constituição. Nem tampouco podem proteger aqueles outros que, sendo constitucionalmente viáveis, recebem tutela bastante por parte dos demais ramos do Direito. De maneira que [...] se são suficientes outros mecanismos jurídicos menos traumáticos que os penais, temos que recorrer a eles e não a estes.
\end{abstract}

Assim, somente os bens jurídicos eligidos pela sociedade como dignos penalmente bem como carentes de sanção penal encontram-se previstos na Constituição Federal, eis que a magnitude de lesão a tais bens jurídicos mostra-se em um grau de importância tal a necessitar do mais alto nível de proteção jurídica: a tutela penal. Somente o Direito Penal oferece meios suficientes aos seus resguardos. Nenhum outro ramo do Direito, nem, tampouco, nenhuma outra forma repressiva, é capaz de cingir-lhes muralhas tamanhas a impedir - ou ao menos dificultar - a violação de tais supremos valores.

\title{
2 Direito penal e sua superabundância legislativa
}

O direito de punir é uma manifestação do poder de supremacia do Estado nas relações com os cidadãos, principalmente na relação indivíduo-autoridade. No aspecto material, o Direito Penal visa evitar a prática de comportamentos considerados pela sociedade como altamente reprováveis e danosos ao organismo social. Referidos atos caracterizam-se por afetar gravemente bens jurídicos indispensáveis à coexistência pacífica, bens jurídicos estes alocados na Constituição Federal, conforme supra exposto. Assim, mostra-se como resultado de escolhas políticas influenciadas pelo tipo de Estado em que a sociedade está organizada.

Pode-se conceituar, então, o Direito Penal como um conjunto de leis que pretende tutelar bens jurídicos cuja violação denomina-se crime e importa uma coerção jurídica particularmente grave, proporcional à gravidade do bem jurídico resguardado. 
Tendo em vista tal supremacia do bem jurídico-penal em relação a quaisquer outros bens jurídicos, a Constituição da República Federativa do Brasil resguardou o Direito Penal de forma diferenciada, destacando-o dos outros ramos do Direito. Assim o fez, inicialmente, em seu art. 22, no qual se encontra particularizada a competência exclusiva da União para legislar sobre matéria penal.

A competência exclusiva da União versa sobre o poder de iniciativa reservado a tal ente. O poder de iniciativa revela a capacidade atribuída pela Constituição para a deflagração do Processo Legislativo. Somente em casos excepcionais a Constituição reserva a iniciativa de projetos de lei sobre determinadas matérias a uma ou algumas pessoas, competindo a elas determinar o momento e a oportunidade de submeter a questão ao crivo do Legislativo (ARAÚJO, 2003, p. 319-320). A iniciativa de uma lei, normalmente, é concorrente, pertencendo simultaneamente aos órgãos e integrantes do poder legiferante. Portanto, a competência exclusiva denota uma maior importância conferida à matéria a ser legislada.

Todavia, possuem a mesma particularidade ora citada os direitos civil, comercial, processual, eleitoral, agrário, marítimo, aeronáutico, espacial e do trabalho, sobre os quais a competência legislativa também é exclusiva da União.

Mostra-se, ainda, como destaque do ramo penalístico em relação às outras ciências do Direito o contido no art. 62 da Carta Magna, o qual veda a emissão de medidas provisórias sobre Direito Penal. A vedação em comento potencializa a importância da disciplina penalística face os outros ramos do Direito. Isto porque a precariedade da espécie normativa medida provisória - que pode ser rejeitada pelo Congresso Nacional, perdendo seus efeitos desde sua edição, nos termos do parágrafo $3^{\circ}$ do art. 62 da Lei Maior - não se compatibiliza com os valores essenciais resguardados pelo Direito Penal, cuja tutela abrange, inclusive, a proteção à liberdade de locomoção do indivíduo.

Porém, tal protecionismo majorado, consubstanciado pela inviabilidade de edição de medidas provisórias, não resta exclusivo do Direito Penal, à medida que recebem o mesmo tratamento os direitos processual penal e processual civil.

Ora, por tratar dos mais elevados bens jurídicos, o Direito Penal não pode ser aquilatado linearmente a citados ramos do Direito. Toda norma é fruto de uma valoração que o legislador faz da realidade e disso resultam eleitos determinados bens que merecem a 
proteção penal. A partir da eleição do bem jurídico-penal podemos analisar seu enquadramento típico, porém não mais sob a perspectiva dogmática da teoria formalista clássica, mas sim com uma leitura constitucional do Direito Penal e do delito, que é obrigatória à medida que a sanção penal incide justamente sobre bens fundamentais da pessoa. Essa eleição, portanto, faz com que os bens jurídicos tutelados pelo Direito Penal representem valores hierarquicamente superiores aos resguardados pelos outros ramos do Direito. Merecem, portanto, proteção ainda mais majorada.

Além da gradação hierarquicamente superior dos bens jurídico-penais em relação a outros bens jurídicos resguardados pelo ordenamento, observa-se que o fato da facilidade de trâmite e aprovação no processo legislativo ordinário desemboca na promulgação de leis insubsistentes cuja discussão não fora devidamente propiciada junto às Casas legislativas. A todo propósito o Estado cria novas leis, sem atentar aos princípios e normas valorativas basilares necessários para tanto.

Depois de dezoito anos da promulgação da Constituição Federal, datada de outubro de 1988, constatou-se que foram produzidas no Brasil 3.510.804 (três milhões, quinhentos e dez mil, oitocentos e quatro) novas normas jurídicas. Em levantamento realizado no ano de 2002, o Instituto Brasileiro de Planejamento Tributário - localizado em Curitiba-PR constatou que se encontravam em vigor, no Brasil, mais de 28.000 (vinte e oito mil) leis e constituições. Entre elas, cerca de 10.000 eram leis ordinárias. No âmbito federal, até 28/02/02 (vinte e oito de outubro de dois mil e dois), foram elaboradas 2.738 (dois mil setecentos e trinta e oito) leis ordinárias, ladeadas por somente 55 (cinqüenta e cinco) leis complementares (GOMES, 2006).

Grande parte dessa superabundância na produção legislativa resultou na farta criação de leis atinentes ao Direito Penal. Desde a época das primeiras codificações até hoje nota-se um intenso e permanente processo de criminalização de condutas, sem preocupação com limites ou mesmo com requisitos materiais mínimos que devem envolver a criação de um tipo penal.

Mediante tal descaso, a Justiça Criminal passou a prestar tarefa de aplicar sanções penais a ilícitos de pequena relevância social ou política. Tal fato restou por ocasionar o fenômeno da paralisante sobrecarga de trabalho, que conduz a conseqüências nefastas, tanto do ponto de vista de sua funcionalidade - gerando morosidade, descrédito, sensação 
de impunidade, de ineficácia da ameaça penal bem como favorecendo a inoperatividade da máquina estatal frente a delitos graves - como sob a visão econômica, ocasionando aumento de gastos com o aparato judiciário, à medida que aumenta o número de julgamentos de infrações cuja ofensividade mostra-se escassa, segundo os parâmetros procedimentais clássicos, majorando ainda o custo de sua execução.

A natural conseqüência da hipertrofia da legislação penal consiste em causar a inviolabilidade operativa do sistema penalístico, decorrendo-se daí prejuízos para a prevenção geral e também para a própria eficácia e reputação do Direito Penal. Até mesmo a segurança jurídica resta prejudicada num universo de leis diuturnamente mutantes e que podem, até mesmo, mostrarem-se divergentes.

Ora, a política criminal deve atuar no sentido da mínima intervenção, em razão dentre outros motivos, como a suma importância do bem jurídico-penal já exposta - dos elevados custos decorrentes da utilização do Direito Penal, incidentes tanto no âmbito social como no âmbito individual.

Ademais, há de se considerar a força que possui a norma penal. Dotada de sanções que na maior parte das vezes atingem a própria esfera de liberdade individual, a construção de uma norma penal deve obedecer fielmente ao elemento constitucional, de modo a refletir demandas plenamente consolidadas e justificadas dentro da sociedade. Neste sentido são os ensinamentos de Antônio Suxberguer (1998, p. 3):

\begin{abstract}
A atuação do Direito Penal atinge diretamente o bem mais valorizado desde o humanismo da Idade Moderna: a liberdade do indivíduo enquanto homem e cidadão. Por conseguinte, a elaboração de normas penais deve ser precedida de um cuidadoso juízo de ponderação, uma parcimoniosa análise que equilibre razoabilidade na aplicação da força do Estado e a devida proteção que determinado bem jurídico requer.
\end{abstract}

A demasiada produção legislativa em matéria penal tem, por vezes, buscado ditar um contexto distante e, até mesmo, absolutamente diverso da realidade. Acaba-se por seguir o caminho inverso da construção de um tipo penal que corresponda eficientemente ao anseio social. O excesso de produção legislativa e a rapidez com que esta ocorre impedem a pormenorizada discussão da real relevância e necessidade da interferência do Direito Penal em determinado assunto. 


\section{Lei ordinária e lei complementar - diferenciação de ritos}

A matéria penal, atualmente, é tratada no âmbito Legislativo mediante a edição de leis ordinárias. No entanto, a) tendo em vista que o bem jurídico-penal, alçado a valor constitucional essencial à vida em sociedade, aloca-se em posição hierarquicamente superior aos bens jurídicos tutelados pelos outros ramos do Direito; b) seguindo-se o caráter de ultima ratio do Direito Penal e, por esse motivo, visando diferenciar potencialmente o legislar da disciplina penal das disciplinas restantes no ordenamento jurídico e, por fim, c) no intuito de insuflar a discussão legislativa sobre a matéria penal, necessária à aplacar a enxurrada de leis produzidas sem a devida análise material e formal; o mais adequado seria que o Direito Penal fosse codificado somente mediante lei complementar. Senão, veja-se.

A lei ordinária tem sua formação decorrente de um processo legislativo regular. Após oferecido o projeto de lei por iniciativa cabível a qualquer das pessoas elencadas no art. 61 da Constituição Federal - quais sejam, membro ou comissão da Câmara dos Deputados, do Senado Federal ou do Congresso Nacional, ao Presidente da República, ao Supremo Tribunal Federal, aos Tribunais Superiores, ao Procurador-Geral da República e aos cidadãos - deflagra-se o processo legislativo. Passa-se à discussão e votação na Câmara dos Deputados e, subsequentemente, no Senado Federal. O projeto de lei aprovado por uma Casa será revisto pela outra, em um só turno de discussão e votação, e enviado à sanção ou promulgação, se a Casa revisora o aprovar (art. 65 da CF). Outrossim, sendo emendado o projeto, voltará à casa iniciadora. Concluída a votação em ambas as casas, o projeto deverá ser enviado ao Presidente da República que, aquiescendo, o sancionará (art. 66 da CF).

Ressalte-se que, na ausência de disposição constitucional específica acerca do quorum de votação necessário à aprovação de um projeto de lei ordinária, mostra-se necessária somente a maioria simples para alcançar-se tal intento, a qual se perfaz com número de votos correspondente a qualquer fração superior à metade dos presentes à sessão.

O processo de inserção de lei complementar no ordenamento jurídico brasileiro, por sua vez, distingue-se daquele referente à legislação ordinária no que concerne ao quorum exigido para a aprovação do projeto correlato, nas duas casas legislativas que compõem o Congresso Nacional. Enquanto que para a anuência de norma extravagante na 
modalidade ordinária impõe-se tão somente a maioria simples, a aceitação de proposta de lei complementar, contudo, subordina-se à aquiescência da maioria absoluta dos membros.

A maioria absoluta resta obtida com a manifestação positiva de mais da metade dos componentes de cada plenário. Logo, a necessidade de porção numericamente superior de parlamentares à sessão designada para a votação de um projeto de lei complementar - em relação àqueles necessários numa votação de lei ordinária - faz com que se opere uma prorrogação na fase de discussão do processo legislativo. É na fase de discussão que as comissões permanentes examinam o projeto no seu aspecto material e formal. Quando do elastecimento dessa etapa, incita-se à análise da adequação do projeto de Lei quanto ao seu conteúdo e interesse público bem como quanto à compatibilidade vertical com a Constituição.

Ao preceituar que determinada matéria dever ser tratada em lei complementar, o Constituinte, constatando previamente a relevância da questão, impõe maior grau de dificuldade para a aprovação. Com tal medida, tem-se o escopo de se intensificar o comprometimento, o envolvimento e a participação dos congressistas, no processo de discussão e aprovação dos documentos legislativos, dos quais emanam intensas ressonâncias na ordem social, política e econômica.

A estipulação das questões que suscitam a formulação de lei complementar resulta de uma avaliação axiológica por parte do legislador constituinte. Coube a este a tarefa de prever, no texto do diploma legal máximo, os temas que, face a importância dos mesmos para o ordenamento jurídico, seriam postulados por meio de lei complementar.

Ressalta-se que são expressamente indicados na Constituição, os temas a serem postulados por meio de lei complementar. Tal conjunto de matérias não pode ser objeto de lei extravagante, sob pena de recair-se em inconstitucionalidade.

A doutrina discute sobre a hierarquia da lei complementar em relação à lei ordinária. Alguns autores, como Manoel Gonçalves Ferreira Filho (apud ARAÚJO; NUNES, 2003), entendem que a lei complementar situa-se entre a emenda constitucional e a lei ordinária, ocupando espaço intermediário entre as duas espécies. De outra arte, Michel Temer (1993), Cláudio Penedo Madureira (2007) e Marcos Antônio Cardoso Souza (2007) defendem o posicionamento de inexistência de hierarquia entre lei complementar e lei 
ordinária, eis que ambas buscam seu fundamento de validade no texto constitucional, possuindo a mesma nascente de validade.

Dentro do mesmo tema, um robusto posicionamento firmou-se ao longo dos anos no Superior Tribunal de Justiça - a quem a Carta da República atribuiu o munus de unificação da Jurisprudência - no sentido da existência de hierarquia entre normas infraconstitucionais ou, mais especificamente, entre leis complementares e ordinárias. A reboque do que vem decidindo referida Corte, as leis complementares, que demandam quorum privilegiado e maioria absoluta para a sua aprovação, seriam hierarquicamente superiores às demais espécies normativas, notadamente, as leis ordinárias, que demandam quorum menos expressivo e maioria simples em seu processo legislativo.

Demais disso, não se trata, aqui, de entregar-se à questão da existência ou ausência de gradação hierárquica entre as leis infraconstitucionais. O que se infere é que a legislação de ordem complementar, por ter seu processo de formação eivado de maior rigidez, resguarda de maneira mais eficaz os bens jurídicos içados ao cume pela sociedade.

Segundo os ensinamentos de Bobbio (1999, p. 71), o ordenamento jurídico compreende "uma totalidade ordenada, um conjunto de entes entre os quais existe certa ordem". A ordem no sistema jurídico brasileiro somente poderá ser alcançada se o Direito Penal - ramo apto a resguardar os bens jurídicos vitais para a sociedade e o Estado - passar a ser codificado mediante lei complementar.

\section{Conclusão}

A atividade legislativa do Estado, na edição de leis em matéria penal, deve atentar aos bens jurídicos-penais vazados na Constituição Federal, estes escolhidos mediante um juízo de cognição no tocante à dignidade penal bem como à carência de sanção penal. Ao resguardar referidos valores constitucionais - estabelecendo entre eles uma certa gradação hierárquica - o legislador constitucional, por motivo de conveniência política, reservou algumas matérias a serem tratadas mediante lei complementar. Essas matérias, consideradas essencialmente relevantes para a condução da Federação - até mesmo como forma de complementação do texto constitucional - somente podem ser regulamentadas mediante quorum privilegiado e maioria absoluta, os quais não são exigidos no processo legislativo deflagrado para a criação das leis ordinárias. 
A exigência de quorum privilegiado para a votação e aprovação de uma lei complementar - que implica na necessidade de maior número de parlamentares presentes à sessão designada - denota uma rigidez formal legislativa majorada, propiciando um elastecimento da fase de discussão legislativa. É nessa etapa que se analisa o projeto de lei em seu aspecto material e formal, examinando-se sua adequação quanto ao conteúdo e interesse público bem como quanto à sua compatibilidade vertical com a Carta Magna.

Propiciando-se maior discussão acerca do projeto de uma lei penal, atender-se-ia de maneira mais efetiva ao princípio da ultima ratio do Direito Penal, de forma a utilizar tão rigoroso sistema de resguardo de bens jurídicos somente nas situações realmente necessárias, o que acarretaria na desejada diminuição numérica de leis penais e no sensível aumento qualitativo das mesmas. Em conseqüência, ocorreria, ademais, a potencialização operacional do sistema penalístico, aproximando-se o dever-ser legislativo à realidade social e contribuindo, inclusive, para a estabilização da segurança jurídica.

Conclui-se, portanto, que o mais adequado - visando à harmonia do ordenamento jurídico brasileiro, à luz dos valores contidos na Constituição Federal de 1988 - seria que o Direito Penal fosse normatizado mediante lei complementar.

\section{Referências}

ARAÚJO, Luiz Alberto David; NUNES, Vidas Serrano Jr. Curso de Direito Constitucional. 7. ed. São Paulo: Saraiva, 2003.

BOBBIO, Norberto. Teoria do ordenamento jurídico. 10. ed. Brasília: Editora Universidade de Brasília, 1999.

GOMES, Luiz Flávio. Norma e Bem Jurídico no Direito Penal. São Paulo: RT, 2002.

. Luiz Flávio. Direito Penal, Ciência do Direito Penal e poder punitivo estatal. Disponível em: <http://www.jus2.uol.com.br/doutrina>. Acesso em: 20 mar. 2007.

. Luiz Flávio. Hiperinflação legislativa: um mal crônico no Brasil. Jus Navigandi,

Teresina, v. 11, n. 1249, 2 dez. 2006. Disponível em:

<http://www.jus2.uol.com.br/doutrina>. Acesso em: 21 mar.2007.

KAZMIERCZAK, Luiz Fernando. Princípio da ofensividade como pressuposto do ius puniendi. Disponível em: <http://www.jus2.uol.com.br/doutrina>. Acesso em: 20 mar. 2007. 
MADUREIRA, Cláudio Penedo. Hierarquia entre normas infraconstitucionais. Disponível em: <http://www.jus2.uol.com.br/doutrina>. Acesso em: 20 mar. 2007.

PALAZZO, Francesco C. Valores Constitucionais e Direito Penal. Porto Alegre: Sergio Antonio Fabris Editora, 1989.

PRADO, Luiz Regis. Bem jurídico-penal e Constituição. 3. ed. São Paulo: RT, 2003. . Luiz Regis. Curso de Direito Penal Brasileiro. 3. ed. São Paulo: RT, 2002. v. 1.

RODRIGUES, João Gaspar. A inutilidade das leis (em demasia). Jus Navigandi, Teresina, v. 7, n. 60, nov. 2002. Disponível em: <http://www.jus2.uol.com.br/doutrina>. Acesso em: 21 mar. 2007.

SIRVINSKAS, Luís Paulo. Introdução ao Estudo do Direito Penal. São Paulo, Saraiva, 2003.

SMANIO, Gianpaollo Poggio. O bem jurídico e a Constituição Federal. Disponível em: <http://www.jus2.uol.com.br/doutrina>. Acesso em: 20 mar. 2007.

SOUZA, Marcos Antônio Cardoso. A hierarquia da lei complementar. Disponível em: <http://www.jus2.uol.com.br/doutrina>. Acesso em: 20 mar. 2007.

SUXBERGUER, Antonio Henrique Graciano. Excessiva produção legislativa de matéria penal. Jus Navigandi, Teresina, v. 2, n. 26, set. 1998. Disponível em:

<http://www.jus2.uol.com.br/doutrina>. Acesso em: 21 mar. 2007.

TEMER, Michel. Elementos de Direito Constitucional. 10. ed. São Paulo: Malheiros, 1993. 
Revista de Direito Público, Londrina, v. 2, N. 2, P. 143-156, MAio/Ago. 2007. 